LA-5641-MS

Informal Report

UC.34

Reporting Date: June 1974 Isoued: June 1974

\title{
Approximate Spherical Blast Theory and Laser-Initiated Pellet Microexplosions
}

by

D. A. Froiwald 
This report wes prepered es en sceount of work sponsored by the United Stetes Government. Neither the Unized States nor the United States Atcmic Enwory Commiation, nor eny of their employes, nor any of their contrectors, subcontrectors, or their emptoyess, makes any umranty, express or im. plied, or animes eny locel liebility of responsibility for the sceurney, com. pleteness or usefulness of eny informution, epperatus, product of process dis. cloesd, or represents that its use would not infringe privately owned rights.

In the interest of prompt ditribution this LAXS ruport was sot edited by the Techaical Informetion stath.

Printed in the United States of Americe. Aratieble from

National Technical Informotion Sorvice

U.S. Departmeat of Commoreo 5285 Port Roral Road

Springtiold, Virginia 22151

Price: Prinled Copy 4.00 Miesoliche 51.45 


\title{
ABSTRACT
}

\begin{abstract}
Equations are presenced whteh describe the shock speed and overpressure as a function of radlus for strong spherfcal blasts in cases where the source wass is not negligible. Approximatons sioliar to those used in the Taylor-Scdov approximate theory are caployed. Sample calculations are presented for a lascr-inltiaced 1-i.lJ (debris energy) pellet aicroexplosion. and cospared to Taylor-Sedov approximece cheory solutions.
\end{abstract}

\section{IKTRODUCTION}

Boch exact and approximate Taylor-Sedov (I-S) theory $^{1-4}$ have long been used to desertbe spherical blast waves emanting frow scrong point explosions. The assumptons that have been used in developing the $T-S$ theory make it valid only in a biffeld regime as outlined below.

Here we address the near-flelt regime where the source mass is not aegligible. Thio 15 of incerest for certaln explostves work and for other problecs such as laser-1nielaced pellec microexplosions. 5-6 The one-digensional plunar near-ficld case has atrcady been created. ${ }^{7}$ Here we address the near-field spherlesl case.

Below we first briefly review the T-S approximate theory to review wechodologies and 1imitations. Then the afternative approxime cheory is developed by using sifllar wethodology. Finally, results of calculations for a $1-4 \mathrm{j}$ pellet-debris miczoexplosion are presenced for both cheorles and compared.

\section{REVIEH OF TAYLOR-SEDOV APPROXIHATE THEORY}

In deriving the $T-S$ theory 10 was assumed that: (1) a large anoune of enorgy $\varepsilon$, is released Instantanequsly ( $\Delta t$ to 0 ) frod a all (negligible) voluse; (2) a sherically expanding strong hydroshock eanates; and (3) che mass of the enersy source $a_{8}$ is negligible; chus either $a_{s}=0$, or the shock tust sweep over a cass of ablent gas $m_{1}$ such that $m_{1}>D_{8}$.

Assumption (3) ensiles definition of a nearficld region wherein $n_{1} \leq n_{*}$, and thus where T-S cheory is not val1d. A aldfield way be defined wheredn $a_{1} \gg B_{s}$, but only ouc to a radius where strong shock theory is valld, 1.e., $P_{2} \gg P_{1}$, where $F_{2}$ is the peak pressuze behind the shock and $P_{1}$ is the amblent gas pressure. In chis region the T-S theory is valid. The far-field reg10n, where the assimpt is: $P_{2} \gg P_{1}$ is not valid and where a veak shock wave and finally an acoustic wave exists, will not be treaced in this report.

Given the above assumptans and certain simllartty argurents, ${ }^{3-4}$ the T-S theory gives the shock position R by

$$
B=E_{0}\left(\frac{E_{s}}{\rho_{1}}\right)^{1 / 5} t^{2 / 5}
$$

where $=$ is tioe, $\rho_{1}$ is amblent gas density, and $\xi_{0}$ is a constant Involving the specific-heat ratio $\gamma$. Spherical sywery $1 \mathrm{~s}$ assumed.

The constant $\xi_{0}$ is evaluated as follous. The energy of the system is assumed constant and equal to $\mathrm{E}_{\mathrm{s}}$ - Then, after energy release,

$$
E_{s}-\int_{0}^{R}\left(\frac{1}{2} u^{2}+e\right) \rho 4 \pi r^{2} d r \text {, }
$$


where $u$ is flor speed, e is specific internal energy, and $\rho$ is density.

Frow strong-shack theory $\left(P_{2} \gg P_{1}\right)$ the flow speed, density, and peak pressure fmediately behind the shock, denoted by subscript (2), are given by

$$
\begin{aligned}
u_{2} & =\frac{2}{y+1} \dot{R}, \\
\rho_{2} & =\frac{y+1}{y-1} \rho_{1}, \\
P_{2} & =\frac{2}{y+1} \dot{R}^{2} \rho_{1},
\end{aligned}
$$

where $R=(d R / d t)$ from Eq. (1) is

$$
\dot{R}=\frac{2}{5} \xi_{0}\left(\frac{E_{s}}{p_{1}}\right)^{1 / 5} t^{-3 / 5}
$$

Also

$$
e_{2}=\frac{J}{Y-1} \frac{P_{2}}{P_{2}}-\frac{2}{(y+1)^{2}} \dot{R}^{2}
$$

In the approximate T-S theory, it is assumed that all the gas swept over ty the shock is concentrated in a thin isotropic shell of thickness $\Delta$, wherein all gas properties are uniform with values given by Eqs. (3) - (5) and Eq. (7). Thus, for conservation of mass (source mass neglected),

$$
\frac{4}{3} \pi R^{3} p_{1}-4 \pi R^{2} \Delta p_{2}
$$

whence

$$
\rho_{2}=\frac{\rho_{1} R}{3 \Delta}
$$

Ualng Eq. (1) and Eqs. (3) - (8) in Eq. (2) and solving for $\xi_{0}$ gives

$$
\xi_{0}=\left(\frac{5}{2}\right)^{2 / 5}\left(\frac{3}{4 \pi}\right)^{1 / 5}\left(\frac{y+1}{2}\right)^{2 / 5} \cdot(9)
$$

Combining Eq. (1) and Eq. (6) yields

$$
\dot{R}=\frac{2}{5} \xi^{5 / 2}\left(\frac{E_{8}}{p_{1}}\right)^{1 / 2} R^{-3 / 2} \text {, }
$$

giving $\dot{R}$ as a function of $R$ for a Biven $E_{j}, o_{1}$, and $Y$.

Combining Zq. (S) and Eq. (10) yields

$$
P_{i}=\frac{2}{\gamma+1}\left(\frac{2}{5}\right)^{2} \xi^{5} E_{k} R^{-3}
$$

giving $P_{2}$ as a function of $R$ for a given $E_{s}$ and $Y$.

The above equations give solutions ascurace to within a few percent ${ }^{3-4}$ of the so-called exact aolutions.
III. APFROXIMATE BLAST THEORY WITH SOURCE MASS

We now consider the case where the source mass is not negligible. We assume, as in the $T-S$ theory, that the source energy $E_{s}$ is delivered in a very short tine $(\Delta t \rightarrow 0)$. We also assume spherical symetry.

$$
\begin{aligned}
& \text { We start with conservation of energy } \\
& \begin{aligned}
E_{s}=E_{d} & +E_{g}=\int_{0}^{r}\left(\frac{l}{2} u_{d}^{2}+e_{d}\right) \rho_{d} 4 \pi r^{2} d r \\
& +\int_{r}^{R}\left(\frac{l}{2} u_{g}^{2}+e_{g}\right) \rho_{g} 4 \pi r^{2} d r
\end{aligned}
\end{aligned}
$$

where the subscript (d) refers to the source debris, the subscript ( $\mathrm{g}$ ) refers to the shock-heated ambient gas, and $r$ refers to the radius of the debris/drivengas interface (ccntact surface); the other terws have the same weaning as in the last section.

In the spirit of the $T-S$ approximate theory the integral for the driven gas in Eq. (12) reduces to

$$
E_{g}=\frac{4}{3} \pi R^{3} \rho_{1}\left(\frac{i}{2} u_{8}^{2}+e_{g}\right)
$$

Using Eqs. (3), (4), and (7) In Eq. (12a) gives

$$
E_{8}=\frac{16}{3} \pi R^{3} \rho_{1} \frac{1}{(\gamma+1)^{2}} \dot{R}^{2} .
$$

For the debris wass, pressure and flow speed must be conserved across the contact surface, 1.e.,

$$
\begin{aligned}
& u_{d}=u_{g}=\frac{2}{\gamma+1} \dot{R} . \\
& P_{d}=z_{B}=\frac{2}{\gamma+1} \dot{R}^{2} \rho_{1},
\end{aligned}
$$

where $P_{g}$ is given by $E q$. (5).

we define the average debris mass density, $\bar{p}_{d}$, as:

$$
\bar{\rho}_{d} \equiv \rho_{s} \frac{R_{s}^{3}}{R^{3}}
$$

where the subscript s refers to the source before explosion. Equation (is) tmplies the assumption that $n_{1}=r, 1, e_{.},(R-r) / r \ll 1$.

Using Eqs. (13) - (15) and employing the functional form of $\mathrm{Eq}$. (7), the approximate expression for $\mathrm{E}_{\mathrm{d}}$ becomes

$$
\begin{gathered}
E_{d}=\frac{4}{3} \pi R^{3} \bar{p}_{d}\left[\frac{1}{2} u_{d}^{2}+e_{d}\right] \ldots \\
=\frac{8}{3} \frac{1}{(\gamma+1)^{2}} p_{s} R_{s}^{3} \dot{R}^{2}+\frac{8}{3} \frac{\pi}{\left(\gamma^{2}-1\right)} p_{1} R^{3} \dot{R}^{2} .
\end{gathered}
$$


Using Eq. (12.a.1) and Eq. (16), the epproxtmate expression for Eq. (12) is

$$
\begin{gathered}
E_{s}=\frac{16}{3} \frac{\pi}{(\gamma+1)^{2}} \rho_{1} R^{3 \cdot R^{2}}+\frac{8}{3} \frac{\pi}{(\gamma+1)^{2}} p_{8} R_{B}^{3} R^{*} \\
+\frac{8}{3} \frac{\pi}{\left(\gamma^{2}-1\right)} \rho_{1} R^{3 \cdot 2} .
\end{gathered}
$$

Given $E_{8}, \gamma, \rho_{1}, \rho_{8}$, and $R_{8}, E_{q}$, (17) can be solved for $\dot{R}$ as a function of $R$. Corresponding $P_{2}^{\prime}$ ' can be found from $\mathrm{Eq}$. (5), and flow speeds from Eq. (3).

\section{COMPUTATIONAL RESULTS}

Shock speeds, $\dot{R}$, were calculated as a function of radius for both $\mathrm{Eq} .(10)$ and $\mathrm{Eq}$. (17), using $\mathrm{E}_{8}$ $=1 \times 10^{6} \mathrm{~J}, \gamma=1,57, \rho_{s}=2 \times 10^{2} \mathrm{~kg} / \mathrm{m}^{3}, R_{s}=10^{-3} \mathrm{~m}$, and $\rho_{1}=10^{-4}$ to $10^{-9} \mathrm{~kg} / \mathrm{m}^{3}$; these are approximate conditions expected in certain leser-initiated fusion experiments involving a deuterium-tritiun ice pellet, where $-1 \mathrm{~kJ}$ of the $7 \mathrm{MJ}$ released would appear in the debris. Corresponding post-shock pressures, $P_{2}$, were calculated by using Eq. (5).

Corputational results for the T-S approximate theory [Eq. (10) and Eq. (5)] are shown in Fig. 1. Note the very high shock speeds $\dot{R}$ for amall radil $R$, namely speeds in excess of the speed of 11ght. This result is obvlously non-physical.

If wthin some very small radius ( $\left.210^{-2} \mathrm{~m}\right)$ the source energy $E_{s}$ is diotributed equally over the source mass, and if all that energy is manfested in kinetic energy, then frow $E_{s}=\frac{1}{2} m_{s} u^{2}$ a flow speed (quasi-free expansion) $u$ of $1.54 \times 10^{6} \mathrm{~m} / \mathrm{s}$ would be predicted. From Eq. (3), a shock speed, $\dot{R}$, of $2.06 \times 10^{6} \mathrm{~m} / \mathrm{s}$ would result.

Computational results for the modified theory, Eq. (17), are shoun: 1n 718.2 , For basll rad11 the results show $\dot{R} \sim 2.06 \times 10^{6} \mathrm{~m} / \mathrm{s}$, in agreement with the speed predicted for small $\mathrm{R}$ for quasi-free expansion.

At higher densicies and/or redil, the revults of F18. 2 show that the flow becomes a blast wave. This result would be expectid as the expending source-mas particles inter.uct with the amblent gas and transfer energy to ablent gas particles, and is predictable when viewing Eq. (17) there the first and the third term on the right-hand side resenble Eq. $(10), 1, E_{\cdots}, E_{g}-p_{1} R^{3 * 2}$.

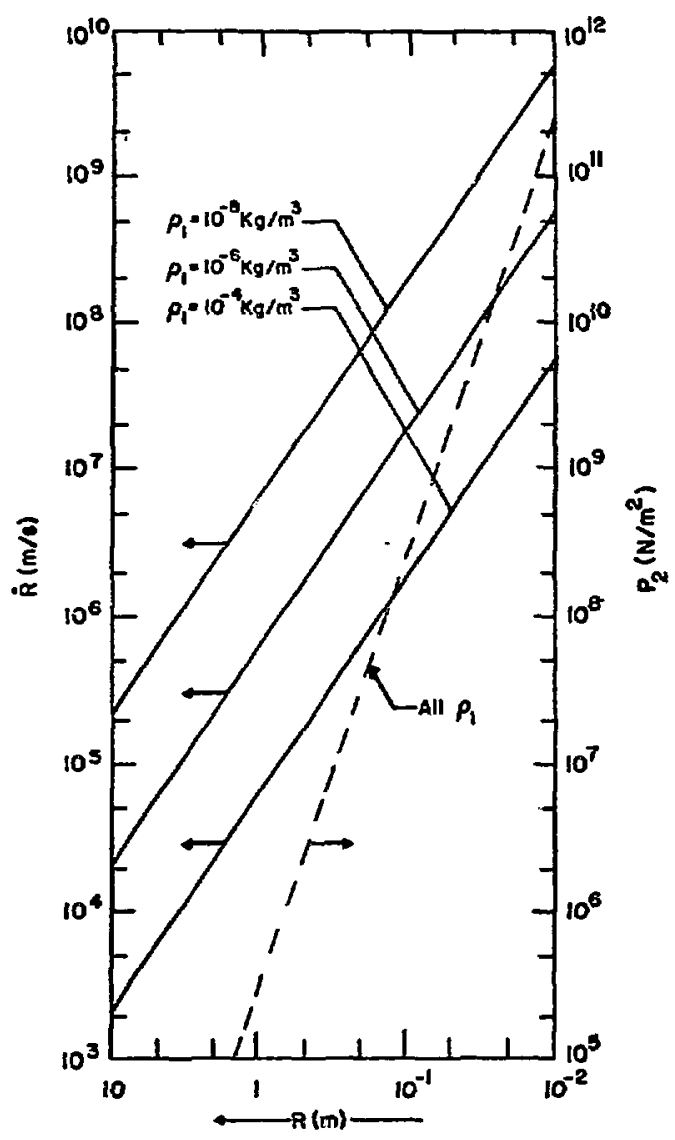

E18. 1. Taylor-Sedor theory solutions for a 1-MU pellet mieroexplosion.

\section{v. DISCUSSION}

The derivation of Eq. (17) admittedly involves several epproximations. The derivation assumes constant $Y$, assumes an ideal gas, and neglects plasma phenomens auch as fast-electron clouds accelerating lons by Coulonb forces. 8 Radiative losses from ionizing ahocks are also neglfcted. Inclusion of such phenomen in the derivat lon would gleld more accurate space- and time-dependent solutions, though numerical rather than analytic solutions would probably be required.

The above analytic regults should be useful in providing estimates of cavity physics phenomena for syseens enalysis work on conceptual laser-fusion reactor concepts. 


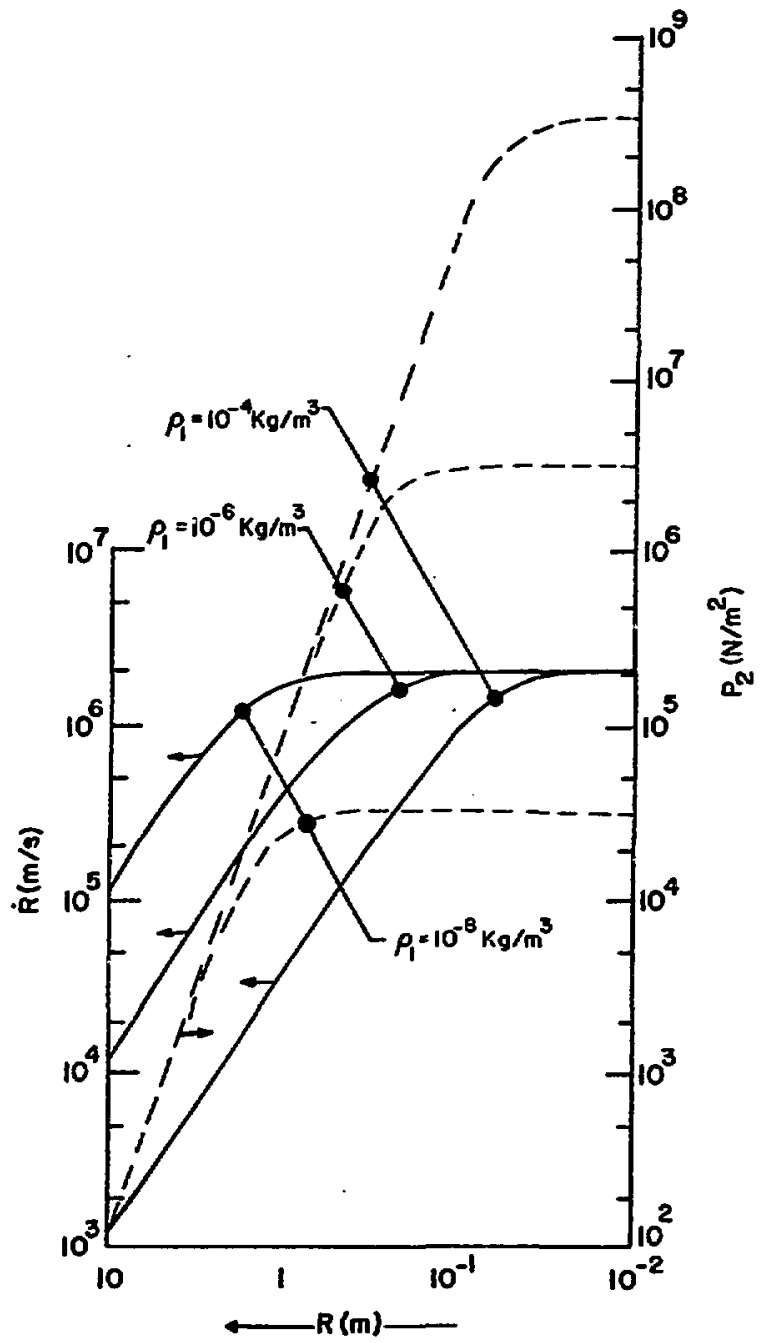

Fig. 2. Solutions with source-mass included for a $1 \mathrm{MJ}$ pellet microexplosion

For example, in some reactor concepts the prompt-x-ray burst from the pellet microexplosion is absorbed in 11thim-wetted first walls of a spherical cavity. 9 The subsequent 11thium vaporization produces an impulse on the first wall (resulting in transient stresses). Subsequent inward expansion of the 1ithium vapor w11, at some time, Interact with the outward-expanding blast driven by the pellet debris. The time, position, and nature of such interaction will depend on the ambient-gas density in the covity. Outward transmitted waves from the interation will subsequently interact with the cavity walls.
Another scenario for dry-wall cavity concepts ${ }^{10}$ again lavolves cavity dynamics. Absorption of the neutron burst in a lithlum blanket surrounding the cavity may result in some cavity wall ringing. The arrival of the pellet debris-driven blast on the wall may amplify or negate an oscillation, depending on cavity dimensions, ambient gas density, and pellet characteristics.

The time of arrival of the pellet debrisdriven blast at various rad11 is one important factor. For $\rho_{1}=10^{-8} \mathrm{~kg} / \mathrm{m}^{3}$ and the pellet characteristics stated above, the T-S theory, Eq. (1), predicts that the blast w11l reach one meter radius at $t \sim 6.23 \times 10^{-8} \mathrm{~s}$. The results of $\mathrm{Fig} .2$ indicate that at one meter radius the arrival time would be $t \sim 4.85 \times 10^{-7}$ s. Thus, altered small-radius flow histories can greatly alter large-radius arrival times.

\section{ACKNOWLEDGEMENTS}

The afd of Evelyn Heck in programing the computer for the various calculations is greatily appreclated.

\section{REFERENCES}

1. G. Taylor, "The Formation of a Blast Wave by a Very Intense Explosion," Proc. Royal Soc. A201 159 (1950).

2. L.D. Landau and E.M. Lifshitz, Fluid Mechanics (Addison-Wesley, Reading, Mass., 1959).

3. Y.B. Zeldovich and Y.P. Razier, Physics of Shock Waves and H1gh-Temperature Eydrodynamic Phenomena, (Academic Press, New York, 1966).

4. E.G. Harris, "Exact and Approximare Treatments of the One-Dimenstonal Blast Wave," Naval Research Laboratory Report 4858 (November 1956).

5. K. Boyer, "Power from Laser-Intttated Nuclear Fuston," Aeronautics and Astronautics 44 (August 1973).

6. J. Nuckolls, J. Enmetr, L. Kood, "Laser-Induced Thermonuclear Fusion," Physics Today (August 1973).

7. D.A. Freiwald, "Approximate Blast Have Theory and Experfwental Data for Shock Trajectories in Linear Explosive-Driven Shock Tubes," J. App1. Phys. 43, 2224 (1972).

8. M. Widner, I. Alexeff, and W.D. Jones, "Plagma Expanston into a Vacuum," Phys, of Fluids $\$ 4$ 795 (1971) 
9. J. Williams, T. Merson, F. Finch, F. Schilling, and T. Frank, "A Conceptual Laser Controlled Thermonuclear Reactor Power Plant," in AEC-CONF-740402 (July 1974).
10.

J. Williams, "Laser Controlled Thermonuclear Reactor Systems Studies," LOS Alamos Scientific Laboratory report in preparation. 